\title{
Current diagnosis of dentin hypersensitivity in the dental office: an overview
}

\author{
David G. Gillam
}

Received: 7 December 2011 / Accepted: 28 November 2012 / Published online: 8 January 2013

(C) The Author(s) 2012. This article is published with open access at Springerlink.com

\begin{abstract}
Objectives The aim of this overview is to consider the problems that may be associated with making a diagnosis of dentin hypersensitivity (DHS) and to provide a basis for clinicians to effectively diagnose and manage this troublesome clinical condition.

Materials and methods A PUBMED literature research was conducted by the author using the following MESH terms: ('diagnosis'[Subheading] OR 'diagnosis'[All Fields] OR 'diagnosis' [MeSH Terms]) AND ('therapy'[Subheading] OR 'therapy'[All Fields] OR 'treatment'[All Fields] OR 'therapeutics'[MeSH Terms] OR 'therapeutics'[All Fields]) AND ('dentin Sensitivity'[MeSH Terms] OR ('dentin'[All Fields] AND 'sensitivity'[All Fields]) OR 'dentin sensitivity'[All Fields]). Variations to the above MeSH terms using terms such as 'cervical', 'dentine' and 'hypersensitivity' as substitutes were also explored, but these searches failed to add any further information.

Results The literature search provided only limited data on specific papers relating to the clinical diagnosis of DHS by dental professionals. Evidence from these published studies would therefore indicate that clinicians are not routinely examining their patients for DHS or eliminating other possible causes of dental pain (differential diagnosis) prior to subsequent management and may rely on their patients' selfreporting of the problem. Furthermore, the findings of the Canadian Consensus Document (2003) would also suggest that clinicians are not confident of successfully treating DHS. Conclusions It is apparent from reviewing the published literature on the diagnosis of DHS that there are a number of
\end{abstract}

D. G. Gillam $(\bowtie)$

Adult Oral Health, Institute of Dentistry, Barts and The London

School of Medicine and Dentistry, Queen Mary University of

London, London E1 2AD, UK

e-mail: d.g.gillam@qmul.ac.uk outstanding issues that need to be resolved, for example, (1) is the condition under- or overestimated by dentists, (2) is the condition adequately diagnosed and successfully managed by dentists in daily practice, (3) is the impact of DHS on the quality of life of sufferers adequately diagnosed and treated and (4) is the condition adequately monitored by clinicians in daily practice. These and other questions arising from the workshop forum should be addressed in well-conducted epidemiological and clinical studies in order for clinicians to be confident in both identifying and diagnosing DHS and subsequent management that will either reduce or eliminate the impact of DHS on their patients' quality of life.

Clinical relevance Clinicians should be made aware not only of the importance of identifying patients with DHS but also of the relevance of a correct diagnosis that may exclude any confounding factors from other oro-facial pain conditions prior to the successful management of the condition.

Keywords Dentin hypersensitivity · Diagnosis · Differential diagnosis $\cdot$ Diagnostic tools $\cdot$ Clinical management

\section{Introduction}

One of the difficulties, facing the clinician when confronted with a patient complaining of dental pain, is that there are a number of clinical conditions that may elicit the same clinical symptoms as dentin hypersensitivity (DHS), and they have to be eliminated before a correct diagnosis of DHS is made. It is important to acknowledge that patients who have been suffering from various types of oro-facial pain in the form of tooth ache or tooth sensitivity may also suffer from various physical or emotional features that can be very upsetting and disturbing to them. For example, they may experience a feeling of despair or helplessness and frustration of not being able to 
cope and a reliance on a clinician to resolve their problem [1]. This, in turn, may make recording a satisfactory history of the condition difficult, and the clinician will need all their skills in obtaining the necessary information relating to the etiology, predisposing factors and clinical symptoms associated with DHS prior to a correct diagnosis which will lead ultimately to a successful conclusion in their treatment strategy. Although there is an abundance of papers in the published literature dealing with DHS, a PUBMED literature search by the author identified only eight specific papers [2-9]. It should, however, be acknowledged that a number of published reviews on DHS management include a section on diagnosis [10-12]. A number of non-peered reviewed papers have also been published, specifically on the diagnosis of DHS, but these may not be readily accessed by a PUBMED search [13, 14]. Evidence from these published studies would therefore indicate that clinicians are not routinely examining their patients for DHS or eliminating other possible causes of dental pain (differential diagnosis) prior to subsequent management and may rely on their patients' self-reporting of the problem $[5,15,16]$. The findings of the Canadian Consensus Document [5], however, would also suggest that clinicians are not confident of successfully treating DHS. Although the evidence from these publications would appear to suggest that dentists may find the diagnosis and management of DHS somewhat contradictory and confusing, there are some positive aspects from the Cunha-Cruz et al. [16] study in that the participating dentists demonstrated an increasing theoretical awareness and knowledge in understanding DHS. There does, however, appear to be discrepancies between the patients' and clinicians' perception of the problem, for example, a number of questionnaire studies [17-22] would appear to suggest that DHS was not considered to be a major problem by patients and, as a consequence, do not normally self-treat or seek treatment from their dentists. According to Gibson et al. [23], most previous studies on DHS failed to consider the impact on the quality of life of those questioned or examined, although studies by Gillam et al. $[19,20]$ attempted to address this issue albeit in a limited manner. Quality of life studies by Gibson et al. [23], Bekes et al. [24] and Boiko et al. [25] using either a Dentin Hypersensitivity Experience Questionnaire or a Quality of Life Questionnaire would appear to show a difference perspective on the impact of DHS on patients on a daily basis. Care, however, has to be taken when comparing questionnaire and clinically based studies for a number of reasons, for example, the highly subjective nature of dental pain and the variation in methodology when assessing DHS in different populations [16, 26, 27]. Generally speaking, questionnaire studies report higher prevalence figures than clinical studies, for example, the reported prevalence of DHS is up to $74 \%$ based on questionnaire studies [16, 19-22], whereas prevalence figures based on clinical findings are generally in the 15-30\% range, depending on the population studied [11]. It may, therefore, be suggested that from an epidemiological perspective that DHS may be overestimated, although from a clinical perspective, the condition may be underestimated by clinicians. The question, however, as to whether these figures represent an underestimation or overestimation of the condition still needs to be resolved in well-conducted studies.

\section{Aim}

The aim of this overview is to consider the problems that may be associated with making a diagnosis of DHS and provide a basis for clinicians to effectively diagnose and manage this troublesome clinical condition.

\section{Materials and methods}

A PUBMED literature research was conducted by the author using the following MeSH terms:

('diagnosis'[Subheading] OR 'diagnosis'[All Fields] OR 'diagnosis'[MeSH Terms]) AND ('therapy'[Subheading] OR 'therapy'[All Fields] OR 'treatment'[All Fields] OR 'therapeutics'[MeSH Terms] OR 'therapeutics'[All Fields]) AND ('dentin sensitivity'[MeSH Terms] OR ('dentin'[All Fields] AND 'sensitivity'[All Fields]) OR 'dentin sensitivity'[All Fields]).

A second search strategy was also conducted by the author using the following MeSH terms:

('organization and administration'[MeSH Terms] OR ('organization'[All Fields] AND 'administration'[All Fields]) OR 'organization and administration'[All Fields] OR 'management'[All Fields] OR 'disease management'[MeSH Terms] OR ('disease'[All Fields] AND 'management' [All Fields]) OR 'disease management'[All Fields]) AND ('diagnosis' [Subheading] OR 'diagnosis'[All Fields] OR ('differential'[All Fields] AND 'diagnosis'[All Fields]) OR 'differential diagnosis'[All Fields] OR 'diagnosis, differential' [MeSH Terms] OR ('diagnosis'[All Fields] AND 'differential'[All Fields]) OR 'differential diagnosis'[All Fields] OR ('differential'[All Fields] AND 'diagnosis'[All Fields])) AND ('dentin sensitivity'[MeSH Terms] OR ('dentin'[All Fields] AND 'sensitivity'[All Fields]) OR 'dentin sensitivity'[All Fields]).

Variations to the above MeSH terms, using terms such as 'cervical', 'dentin' and 'hypersensitivity' as substitutes, were also explored, but these searches failed to add any further information.

The criteria for acceptance of the published papers for the purposes of this overview paper were based primarily on 
whether the main MeSH terms such as diagnosis and differential diagnosis were in the title of the publication.

\section{Results}

The PUBMED search yielded only eight papers specifically dealing with diagnosis of DHS in the title of the publication [2-9]. Although if the search was expanded to include other $\mathrm{MeSH}$ terms such as clinical management and therapeutic approaches, then further papers would be forthcoming, and these would generally have a section on diagnosis and differential diagnosis. Non-peer-reviewed papers would also be excluded by a PUBMED search but may be identified using non-medical search engines such as Google.

\section{Discussion}

According to Addy et al. [28] and the Canadian Consensus Document [5], DHS has been defined as 'pain derived from exposed dentin in response to chemical, thermal tactile or osmotic stimuli which cannot be explained as arising from any other dental defect or disease (previously, the term pathology was used by Addy [29])'. More recently, several investigators $[28,30]$ have suggested that clinicians should distinguish between those individuals complaining of DHS who have relatively healthy mouths with those who complain of DHS as a result of periodontal disease and/or its treatment. Recently, the term root sensitivity or root dentin sensitivity (RDS) or root dentin hypersensitivity has been used to describe sensitivity arising from periodontal disease and its treatment $[10,31]$. Currently, however, most of the reported prevalence studies do not distinguish between DHS and RDS, and as a consequence, there are limited data on the condition. The importance of the definition as suggested by Addy et al. [28] and from the Canadian Consensus Document (5) is that it provides a very useful clinical description of the condition and suggests the need to exclude other forms of tooth pain or sensitivity. In other words, the definition of DHS is one of exclusion.

Pain arising from DHS may, however, be variable in character, ranging in intensity from mild discomfort to extreme severity, and the degree of pain experienced by patients varies in different teeth and in different persons as it is related to the patient's pain tolerance as well as to emotional and physical factors [10]. Most patients describe the pain arising from DHS as being rapid in onset, sharp in character and of short duration [28]. According to Gillam et al. [10] and Gillam and Orchardson [27], patients self-report a wide variety of pain producing conditions together with a range of different stimuli which are thermal, osmotic, chemical, physical or mechanical in nature. It is important for the clinician to acknowledge that some of these stimuli such as cold air from a dental air syringe or water used in a mouthrinse together with various dental instruments such as explorer probes and scalers together with suction from a dental aspirator tip may also cause discomfort. This, in turn, may prevent the clinician from successfully pursuing a thorough examination of the patient and subsequently failing to determine a correct diagnosis of the problem. It is also evident that despite a number of peer-reviewed papers on the methodology involved in the evaluation of DHS [5, 26, 27, 32], there appears to be no commonly accepted methodology used in clinical practice [16].

Prior to considering any treatment strategy for the management of DHS, it is important to note from the published literature that there are a number of individuals who may be at risk from dentin hypersensitivity, for example [33], as follows:

- Overenthusiastic brushers

- Periodontal treated patients

- Bulimics

- People with xerostomia

- High-acid food/drink consumers

- Older people exhibiting gingival recession

- Chewing 'smokeless' or 'snuff' tobacco

A further consideration which is relevant to this discussion is the apparent differences in perception between patients who self-report the problem and the clinician who has to diagnose and treat the condition. For example, the prevalence figures cited in the published literature are usually dependent on the methodology employed in a particular study $[26,27]$. In general terms, the results from questionnaire studies rely on the patients' perception of the condition which may tend to overestimate the problem. This may be due, in part, to the patient's difficulty in determining the type of dental pain they may be experiencing at the time. Examination of patients who complain of DHS generally produces slightly lower figures of prevalence compared to those recorded by questionnaire alone [34]. This apparent disparity may therefore lead to some confusion as to whether the condition is under or overestimated, and as such needs to be investigated in well-conducted studies. Previous questionnaire studies by Gillam et al. [19, 20] would appear to indicate that most patients did not perceive DHS as a severe dental problem and, consequently, did not seek treatment from their dentist or self-treat with recognised over-thecounter products. The impact on the quality of life of these patients, however, was only addressed in a limited manner [23], although these studies reported that some patients were unable to carry out daily activities due to their dental problem. For example, $28.2 \%$ of participants were unable to drink cold water without some form of discomfort, and $26.5 \%$ could not eat ice cream without discomfort. 


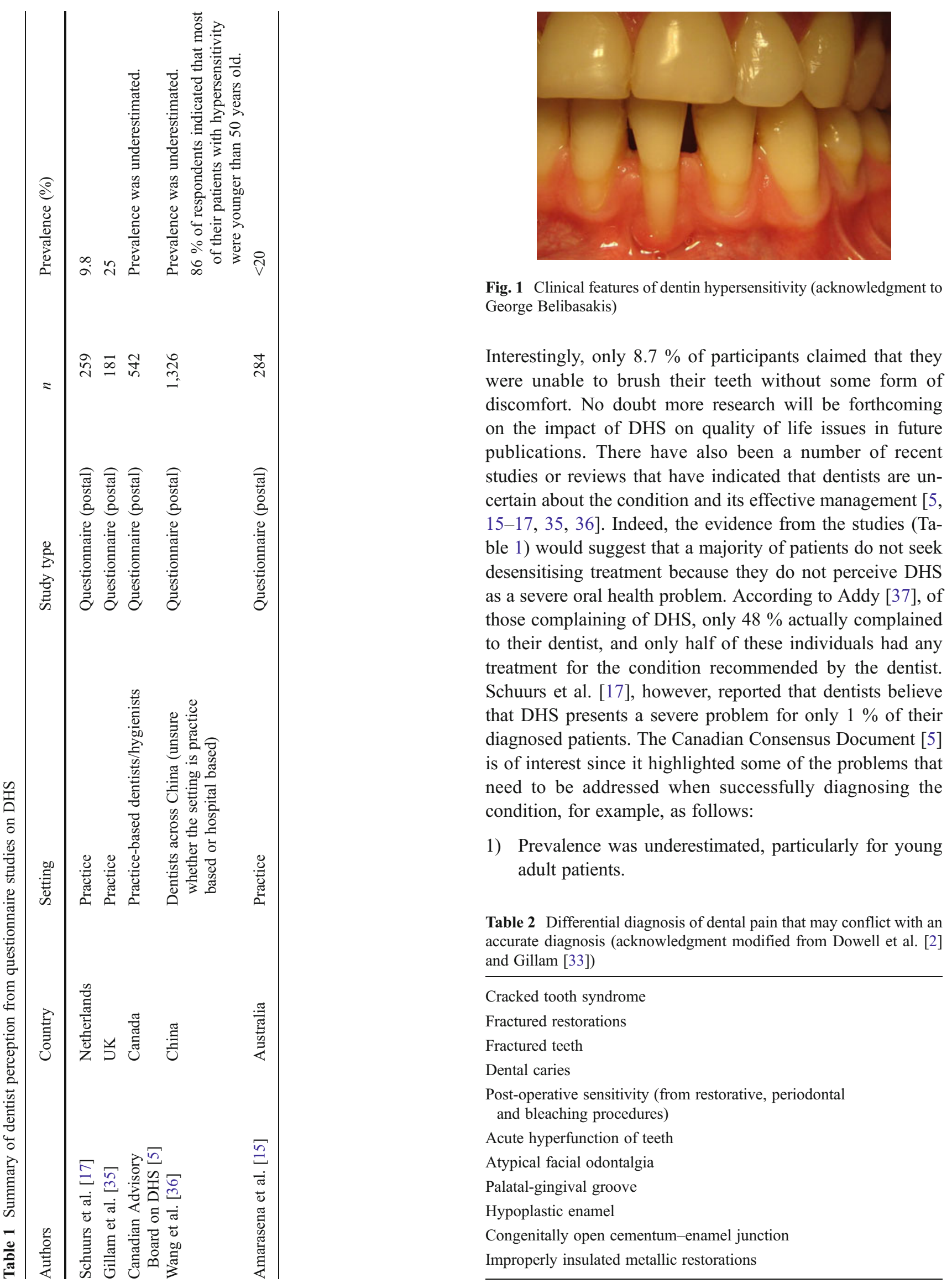


Table 3 Stimuli used to assess dentin hypersensitivity in the clinical setting (acknowledgment reproduced from Gillam et al. [27])

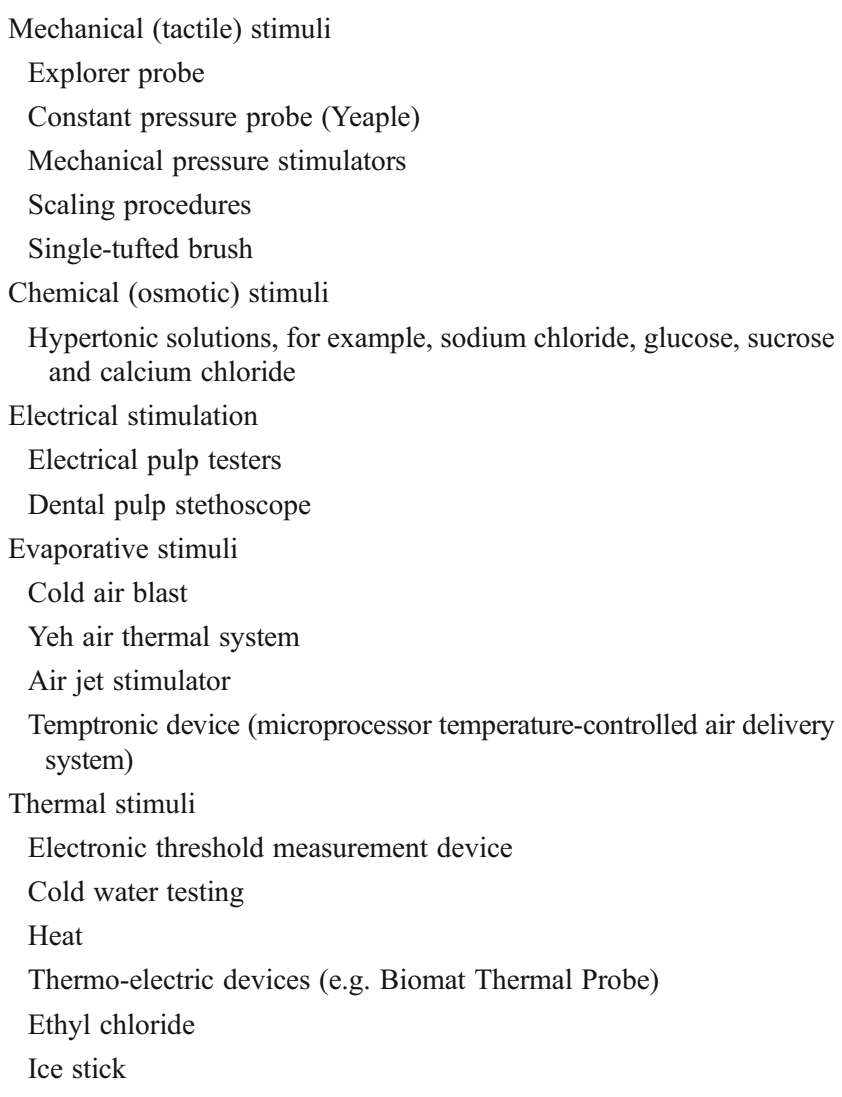

NB: Hydrostatic pressure evaluation has also been reported in the literature, but may be considered impractical for use in clinical studies (acknowledgment to Gillam et al. [27])
2) Screening was not routinely conducted, except when prompted by patients.

3) Fewer than half of the respondents considered a differential diagnosis, even though DHS is, by definition, a diagnosis of exclusion.

4) About $50 \%$ of respondents reported that they lacked confidence in managing their patients' pain.

It is clear from the findings and conclusions from these studies that there appears to be a lack of awareness among clinicians of the importance of a correct diagnosis of DHS which, in turn, will result in incorrect treatment strategies that will frustrate both patient and clinician alike. Furthermore, it is evident that clinicians mainly rely on their patients' self-reporting of pain which may have been spontaneous or generated via the clinician's query rather than clinical evaluation [16].

History taking, oral examination and diagnosis

The diagnosis of DHS would appear initially to be fairly straightforward, and yet as previously discussed, there appears to considerable confusion when attempting to identify through successful diagnosis for those patients who suffer from it [5]. In fairness to clinicians, the condition is highly subjective in nature, and there are a number of confounding problems that may make a correct diagnosis problematic. Patients who may complain of tooth pain including DHS may also suffer from various physical or emotional features that can be very upsetting and disturbing to them. For example, they may experience a feeling of despair or helplessness and frustration of not being able to cope and a reliance on a dental professional to resolve their problem

Table 4 Differential diagnosis of dental pain that may conflict with an accurate diagnosis of DHS (acknowledgment to Aghabeigi [40], reproduced from Gillam [14])

\begin{tabular}{|c|c|c|c|c|c|}
\hline Etiology & $\begin{array}{l}\text { Pain character } \\
\text { and timing }\end{array}$ & Pain intensity & Proving factors & Relieving factors & Associated features \\
\hline $\begin{array}{l}\text { Dentin } \\
\text { hypersensitivity }\end{array}$ & $\begin{array}{l}\text { Sharp, stabbing, } \\
\text { stimulation evoked }\end{array}$ & Mild to moderate & $\begin{array}{l}\text { Thermal, tactile, } \\
\text { chemical, osmotic }\end{array}$ & $\begin{array}{l}\text { Removal of the } \\
\text { stimulus }\end{array}$ & $\begin{array}{l}\text { Attrition, erosion, } \\
\text { abrasion, abfraction }\end{array}$ \\
\hline Reversible pulpitis & Sharp, stimulation evoked & Mild to moderate & Hot, cold, sweet & $\begin{array}{l}\text { Removal of the } \\
\text { stimulus }\end{array}$ & Caries, restorations \\
\hline Irreversible pulpitis & $\begin{array}{l}\text { Sharp, throbbing, } \\
\text { intermittent/continuous }\end{array}$ & Severe & $\begin{array}{l}\text { Hot, chewing, } \\
\text { lying flat }\end{array}$ & $\begin{array}{l}\text { Cold in the late } \\
\text { stages }\end{array}$ & Deep caries \\
\hline $\begin{array}{l}\text { Cracked tooth } \\
\text { syndrome }\end{array}$ & Sharp intermittent & Moderate to severe & Biting, 'rebound pain' & & Trauma, parafunction \\
\hline Periapical periodontitis & Deep, continuous boring & Moderate to severe & Biting & $\begin{array}{l}\text { Removal of } \\
\text { trauma }\end{array}$ & $\begin{array}{l}\text { Periapical redness, } \\
\text { swelling, mobility }\end{array}$ \\
\hline $\begin{array}{l}\text { Lateral periodontal } \\
\text { abscess }\end{array}$ & Deep continuous aching & Moderate to severe & Biting & & $\begin{array}{l}\text { Deep pockets redness } \\
\text { and swelling }\end{array}$ \\
\hline Pericoronitis & Continuous & Moderate to severe & Biting & $\begin{array}{l}\text { Removal of } \\
\text { trauma }\end{array}$ & $\begin{array}{l}\text { Fever, malaise, imprint } \\
\text { of upper tooth }\end{array}$ \\
\hline $\begin{array}{l}\text { Dry socket } \\
\text { (acute alveolar osteitis) }\end{array}$ & $\begin{array}{l}\text { Continuous } 4-5 \text { days } \\
\text { post-extraction }\end{array}$ & Moderate to severe & & Irrigation & $\begin{array}{l}\text { Loss of clot, } \\
\text { exposed bone }\end{array}$ \\
\hline
\end{tabular}


Fig. 2 Methods used by dentists $(N=209)$ in the Northwest Practice-based REsearch Collaborative in Evidence-based DENTistry to diagnose dentin hypersensitivity (acknowledgment to CunhaCruz et al. [16])

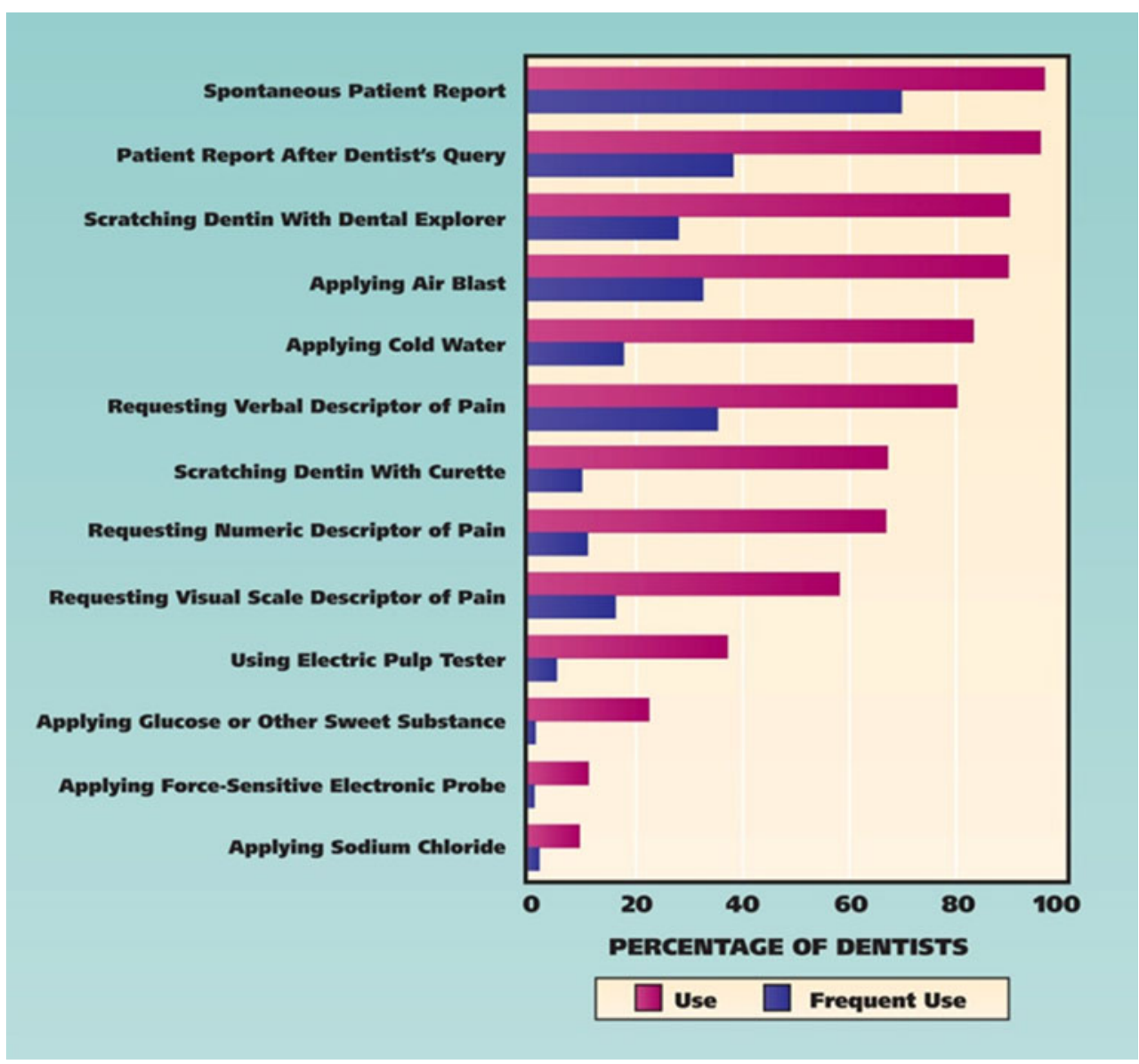

[1]. This, in turn, may make recording a satisfactory history of the condition difficult, and the clinician will need all their skills in obtaining the correct diagnosis which will lead to a successful conclusion in their treatment strategy. In a busy dental practice, this may take time, and the clinician needs to be a good listener, sympathetic and patient in order to elicit the necessary information from the patient. Indeed, clinicians should take heed of the famous quote by William Osler (1849-1919) when examining their patients: 'Listen to your patient he or she will tell you the diagnosis' [38].

Two suggestions may, therefore, be relevant when examining a patient with DHS:

1. How to identify (diagnosis and differential diagnosis)

2. How to assess (measurement)

\section{How to identify (diagnosis and differential diagnosis)}

The word diagnosis (Latin) is derived from diagignōskein (Greek) meaning to distinguish (from dia-+gignōskein to know [39] and may be considered in the following manner:

1. The art or act of identifying a disease from its signs and symptoms
2. The decision reached by diagnosis

3. A diagnosis made by eliminating other possible causes of disease symptoms

In other words, making a particular diagnosis would attempt to exclude or shut out (Latin excludere) other similar signs and symptoms which may complicate a correct diagnosis of a condition and subsequent treatment. This would, therefore, satisfy the previously stated comment that DHS is, by definition, a diagnosis of exclusion; care, however,

Fig. 3 Flowchart for the clinical management of dentin hypersensitivity (adapted with permission of George Warman Publications, Ltd., UK [11, 13]). Notes 1 pain evoked by thermal, evaporative (jet of air) probe and osmotic or chemical stimuli as part of the clinical examination of the patient; 2 alternative causes of tooth pain include caries, chipped teeth, cracked tooth syndrome, fractured or leaking restorations, gingivitis, palatogingival grooves, post-restoration sensitivity or pulpitis; 3 treatment may be delivered in a stratified manner, as follows, with localised or severe dentin sensitivity, and dental professionals may prefer to treat the patient directly, using an in-office procedure; 4 some form of followup is recommended. However, the follow-up interval may vary, depending on the patient's or dental professional's preference and circumstances; 5 if mild sensitivity persists at the initial follow-up appointment, the dental professional may continue with preventive and at-home therapies. If the sensitivity is more severe, some form of in-office treatment may be appropriate 


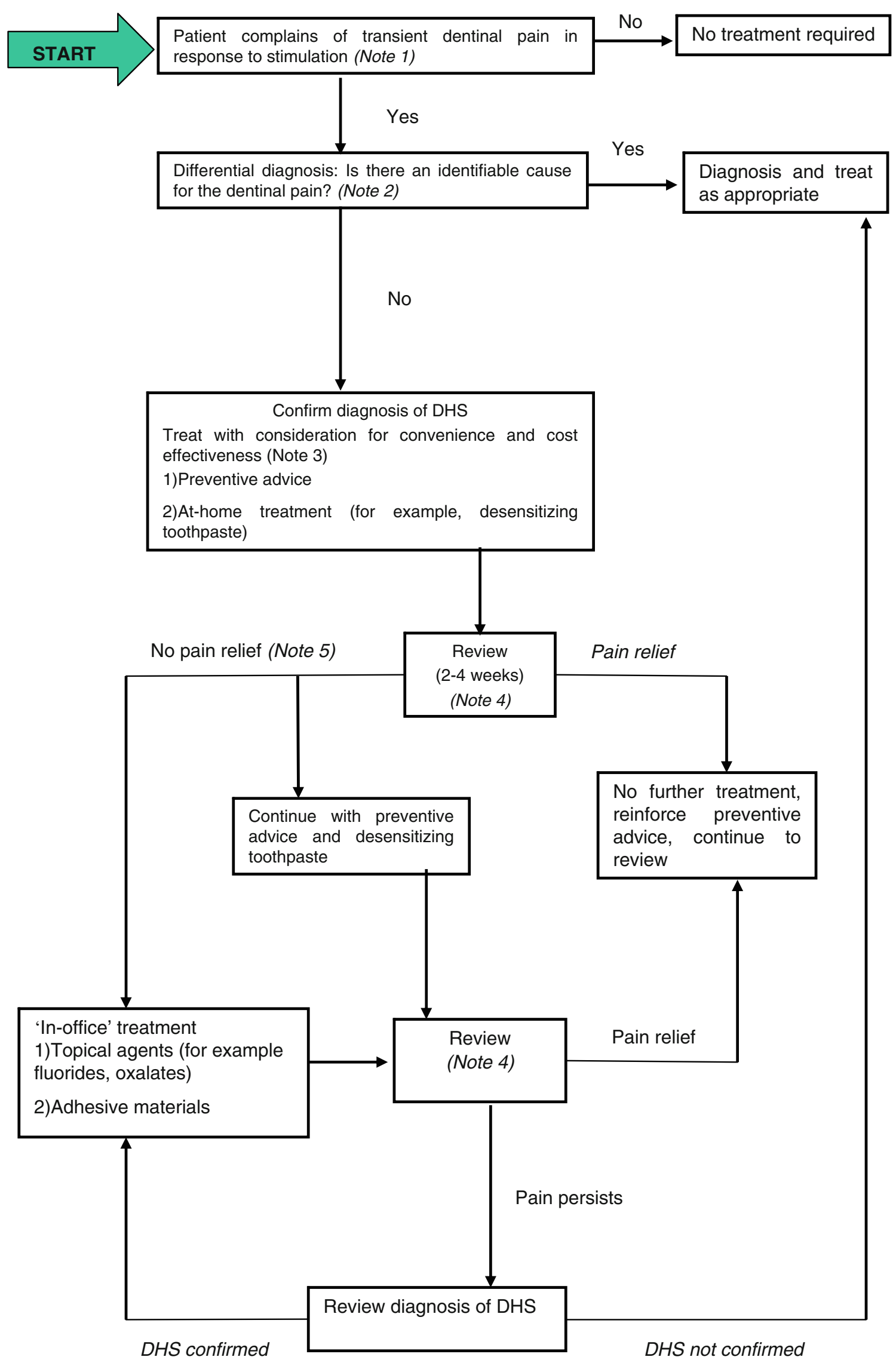


should be taken not to force this assumption too far as a diagnosis (according to the above definition) will exclude or shut out other confounding features.

Once the history taking has been completed, the patient can be examined in order to diagnose the presenting problem that patient may have. This will include all extra- and intra-oral tissues (including palpation) in a thorough and systematic manner; various investigational aids such as radiographs, vitality tests, etc. relevant to the oral examination may be taken, and these should be able to confirm the clinical diagnosis based on a thorough history. Identification of localised areas of exposed buccal or facial aspects of the dentin may be investigated using an explorer probe and gently drawing it across the dentin surface (Fig. 1). This procedure may elicit a response from the patient, although it is generally accepted that a blast of cold air from a dental air syringe is more likely to record a response from the patient if their problem is one of DHS. The clinician, however, should be aware of a number of conditions that may also cause similar symptoms, and these may include conditions such as a cracked tooth syndrome, dental caries, reversible and irreversible pulpitis, fracture teeth or restorations, postoperative sensitivity (from restorative, periodontal and bleaching procedures), atypical facial pain, etc. (Table 2) which may require a prolonged clinical examination with various diagnostic tests [vitality (pulp tester, ethyl chloride, ice stick) percussion, radiographic, etc.] (Table 3) [16, 26, 27]. A useful tip in diagnosing some of these conditions has been previously suggested, for example, the application of a varnish such as Duraphat on the exposed root surface with the clinician evaluating the severity of the problem before and after application with an air blast from a dental air syringe. For diagnosing a tooth with a cracked tooth syndrome, the use of a diagnostic local infiltration or inferior dental block or the use of a tooth sleuth may be of benefit. Previous history of any restorative procedures (restorative, periodontal, bleaching) may also help eliminate other possible causes of dental pain. A useful guide for distinguishing the different types of dental pain which may lead to a correct diagnosis of DHS has been suggested by Aghabeigi [40] (Table 4).

\section{How to assess (measurement)}

Following the evaluation of the history of the presenting complaint where the clinician has elicited the relevant information about the character, site, onset, duration, periodicity and severity of the problem that the patient may have, together with a thorough clinical examination the clinician may wish to determine the severity of DHS before commencing any treatment. Generally, there are a number of methodological approaches to both subjective and clinical evaluation of DHS. This has been extensively reviewed by a number of investigators and has been published in peerreviewed journals $[16,26,27,32]$ (Table 3, Fig. 2). However, for the day to day diagnosis of DHS in dental practice, this may be broadly considered in terms of tactile (probe) and thermal/evaporative (cold air blast) evaluation together with a subjective response from the patient using a recognised pain scale such as a visual analog scale (VAS) (no pain to worse pain experienced) or simply relate the severity as a $0-10$ numerical score. It is important, however, for the clinician to conduct this part of the diagnostic process in a systematic manner and record his/her findings in the patient's clinical record.

Once a diagnosis of DHS has been established, the clinician can then suggest the various treatment options that would benefit his/her patient, and this will depend on the extent and severity of the problem. It is important to recognise that both counselling and preventive aspects of the diagnosis and management of DHS should not be forgotten. For example, the use of diet history sheets, to help both the patient and the clinician identify the various erosive elements in the form of food and drinks, is a valid tool in this process, together with the identification and elimination of any predisposing factors that are implicated in DHS. Furthermore, it is imperative that in any subsequent treatment, the patient is monitored and reviewed in a management strategy based on recognised treatment paradigms $[5,10,11,13]$ (Fig. 3).

\section{Conclusion}

It is apparent from reviewing the published literature on the diagnosis of DHS that there are a number of outstanding issues that need to be resolved, for example, (1) the condition under- or overestimated by epidemiologists and dentists, (2) the condition adequately diagnosed and successfully managed by dentists in daily practice, (3) the impact of DHS on the quality of life of sufferers adequately diagnosed and treated and (4) the condition adequately monitored by clinicians in daily practice. These and other questions arising from the workshop forum should be addressed in well-conducted epidemiological and clinical studies in order for clinicians to be confident in both identifying and diagnosing DHS and subsequent management that will either reduce or eliminate the impact of DHS on their quality of life.

Conflict of Interest The author declared that there are no conflicts of interests in writing this article.

Open Access This article is distributed under the terms of the Creative Commons Attribution License which permits any use, distribution, and reproduction in any medium, provided the original author(s) and the source are credited. 


\section{References}

1. Pau AKH, Croucher R, Marcenes W (2000) Perceived inability to cope and care-seeking in patients with toothache: a qualitative study. Brit Dent J 189:503-506

2. Dowell P, Addy M, Dummer P (1985) Dentin hypersensitivity: etiology, differential diagnosis and management. Br Dent J 158:92-96

3. Wakano Y, Ishida H (1985) Dentin sensitivity following periodontal rehabilitation. Shikai Tenbo, Aug; Spec No:143-4. (Article in Japanese)

4. Richmond NL (1993) Dental hypersensitivity: recent advances in diagnosis and treatment. J Indiana Dent Assoc 72(1):20-22, Review

5. Canadian Advisory Board on Dentin Hypersensitivity (2003) Consensus-based recommendations for the diagnosis and management of dentin hypersensitivity. J Can Dent Assoc 69:221-226

6. Qiang ZK, Xue Y, Zhi Z (2009) Guideline for the diagnosis and management of dentin hypersensitivity. Chinese Stomatological Association Expert Committee on Dentin Hypersensitivity 44: 132-134

7. Porto ICCM, Andrame AKM, Montes MAJR (2009) Diagnosis and treatment of dentinal hypersensitivity. J Oral Sci 51:323-332

8. Cummins D (2009) Dentin hypersensitivity: from diagnosis to a breakthrough therapy for everyday sensitivity relief. J Clin Dent 20:1-9

9. Terry DA (2011) Cervical dentin hypersensitivity: etiology, diagnosis and management. Dent Today 30:61-62, 64, 66

10. Gillam D, Orchardson R (2006) Advances in the treatment of root dentin sensitivity: mechanisms and treatment principles. Endod Top 13:13-33

11. Orchardson R, Gillam DG (2006) Managing dentin hypersensitivity. J Am Dent Assoc 137:990-998, quiz 1028-1029

12. West NX (2007) The dentin hypersensitivity patient - a total management package. Int Dent J 57(Suppl 1):411-419

13. Gillam DG (2009) Diagnosis and management of dentin hypersensitivity. Dental Tribune 10:11, 12, 14

14. Gillam DG (2010) Dentin hypersensitivity: an introduction to differential diagnosis. Dent Pract 48(32):34-35

15. Amarasena N, Spenser J, Ou Y, Brennan D (2010) Dentin hypersensitivity-Australian dentists' perspective. Australian Dent J 55:181-187

16. Cunha-Cruz J, Wataha JC, Zhou L, Manning W et al (2010) Treating dentin hypersensitivity: therapeutic choices made by dentists of the Northwest PRECEDENT network. JADA 141:1097-11, 5

17. Schuurs AHB, Wesselink R, Eijkman MAJ, Duivevnvoorden HJ (1995) Dentists' views on cervical hypersensitivity and their knowledge of its treatment. Endod Dent Traumatol 11:240-244

18. Chabanski MB, Gillam DG, Bulman JS, Newman HN (1996) Prevalence of cervical dentin sensitivity in a population of patients referred to a specialist Periodontology Department. J Clin Periodontol 23:989-992

19. Gillam DG, Seo HS, Bulman JS, Newman HN (1999) Perceptions of dentin hypersensitivity in a general practice population. J Oral Rehab 26:710-714

20. Gillam DG, Seo HS, Newman HN, Bulman JS (2001) Comparison of dentin hypersensitivity in selected occidental and oriental populations. J Oral Rehabil 28:20-25

21. Irwin CR, McCusker P (1997) Prevalence of dentin hypersensitivity in a general dental population. J Irish Dent Assoc 43:7-9
22. Clayton DR, McCarthy D, Gillam DG (2002) A study of the prevalence and distribution of dentin sensitivity in a population of 17-58-year-old serving personnel on an RAF base in the Midlands. J Oral Rehab 29:14-23

23. Gibson B, Boiko OV, Baker S, Robinson PG et al (2010) The everyday impact of dentin sensitivity: personal and functional aspects. Soc Sci Dent 1:11-20

24. Bekes K, John MT, Schaller HG, Hirsch C (2009) Oral healthrelated quality of life in patients seeking care for dentin hypersensitivity. J Oral Rehabil 36:45-51

25. Boiko OV, Baker SR, Gibson BJ, Locker D et al (2010) Construction and validation of the quality of life measure for dentin hypersensitivity (DHSEQ). J Clin Perio 37:973-980

26. Gillam DG, Newman HN (1993) Assessment of pain in cervical dentinal sensitivity studies: a review. J Clin Periodontol 20:383-394

27. Gillam DG, Orchardson R, Närhi MVO, Kontturi-Närhi V (2000) Present and future methods for the evaluation of pain associated with dentin hypersensitivity. In: Addy M, Embery G, Edgar WM, Orchardson R (eds) Tooth wear and sensitivity. Martin Dunitz, London, pp 283-297

28. Addy M (2000) Dentin hypersensitivity: definition, prevalence distribution and etiology. In: Addy M, Embery G, Edgar WM, Orchardson R (eds) Tooth wear and sensitivity. Martin Dunitz, London, pp 239-248

29. Addy M, Mostafa P, Absi EG, Adams D (1985) Cervical dentin hypersensitivity. Etiology and management with particular reference to dentifrices. In: Rowe NH (ed) Proceedings of symposium on hypersensitive dentin - origin and management. University of Michigan, pp 147-167

30. Sanz M, Addy M (2002) Group D summary. J Clin Periodontol 29 (Suppl 3):195-196

31. Troil BV, Needleman I, Sanz M (2002) A systematic review of the prevalence of root sensitivity following periodontal therapy. J Clin Periodontol 29(Suppl 3):173-177

32. Holland GR, Nähri MN, Addy M, Gangarosa L, Orchardson R (1997) Guidelines for the design and conduct of clinical trials on dentin hypersensitivity. J Clin Periodontol 24:808-813

33. Gillam DG (2009) The management of dentin hypersensitivity. Dental Nurse 5:451-456

34. Flynn J, Galloway R, Orchardson R (1985) The incidence of 'hypersensitive' teeth in the West of Scotland. J Dent 13:230-236

35. Gillam DG, Bulman JS, Eijkman MAJ, Newman HN (2002) Dentists' perception of dentin hypersensitivity and knowledge of its treatment. J Oral Rehabil 29:219-225

36. Wang WJ, Rong WS, Hu D (2009) Understanding and clinical management of dentin hypersensitivity of Chinese dentists. In: IADR/AADR/CADR 87th general session and exhibition (April 1-4, 2009). Exhibition Hall D (Miami Beach Convention Center)

37. Addy M (2002) Dentin hypersensitivity: new perspectives on an old problem. Int Dent J 52(Suppl 1):367-375

38. Smith R (2003) Thoughts for new medical students at a new medical school. BMJ 327:1430-1433

39. Mosby's Medical Dictionary, 8th edition. (C) 2009, Elsevier http:// www.merriam-webster.com/dictionary/diagnosis

40. Aghabeigi B (2002) Dental pain. In: Zakrzewska JM (ed) Pain research and clinical management: assessment and management of orofacial pain, vol. 4. Elsevier, Amsterdam, pp 181-189 